\title{
Effect of an 8-week Judo Course on Muscular Endurance, Trunk Flexibility, and Explosive Strength of Male University Students
}

\author{
Mohammed Hamdan Hashem Mohammed and Hong Jun Choi \\ King Fahd University of Petroleum \& Minerals, Physical Education Department, Dhahran, Saudi Arabia
}

\begin{abstract}
A B S T R A C T
Judo is a worldwide sport played as a main competition in the Olympic Games and World Judo Championship with different age categories present for each competition. The level of physical fitness, tactical skills, and techniques required in judo is high as it is a high-intensity short exercise done in a periodic manner. There are very few studies that find the effects of judo exercises on judo non-athletes. The purpose of the research was to determine the impact of an 8-week judo course on the muscular endurance, trunk flexibility, and explosive strength of male university students. Twenty students had complete data after the course. Pre and post measurements were obtained for standing long jump, sit-ups, and sit and reach to assess explosive strength, abdominal muscle endurance, and flexibility, respectively. The data were tested for normality using the Shapiro-Wilk Test. Pre and post data which were normal were compared with paired t-test, while non-normal data were compared with the Wilcoxon Signed Rank Test. Statistical significance was set at $p<0.05$, while Cohen $d>0.2$ was considered of practical significance. There were significant improvements from pre to post in all measured parameters $(p<0.05$, Cohen $d>0.2)$. The increase in values of standing long jump, sit-ups, and sit and reach at end of the course is evidence that the explosive strength, muscular endurance, and trunk flexibility of the students improved, respectively. Thus, there is evidence that the course improved some aspects of their health-related fitness even though they were not judo athletes.
\end{abstract}

Key words: judo, university students, health-related fitness, physical education

\section{Introduction}

Judo is a worldwide sport played as a main competition in the Olympic Games and World Judo Championship, with different age categories present for each competition (Franchini, Del Vecchio, Matsushigue, \& Artioli, 2011). The level of physical fitness, tactical skills, and techniques required in judo is high (Franchini, Takito, Kiss, \& Strerkowicz, 2005) as it is a high-intensity short exercise done in a periodic manner (Degoutte, Jouanel, \& Filaire, 2003). A typical judo match lasts for 3-4 minutes. The classifications in each competition represent the differences in tactical and physiological aspects (Franchini et al., 2011).

Given an increasing prevalence of obesity due to rising physical inactivity (World Health Organization, 2016), offering a physical education (PE) course to students in their early university years is a useful contribution to increasing their physical activity levels. Physical activity has been shown to have positive benefits, like preventing obesity, diabetes, and cancer (Warburton, Nicol, \& Bredin, 2006). Moderate intensity physical activity done for at least 30 minutes is recommended for people who are healthy, or do not have any disease related to physical activity if they are between 18-65 years old (Haskell et al., 2007).

Very few studies that find the effects of judo exercises on non-athletes have been found. But it has been reported that martial arts programs do have positive fitness benefits for those who practice them (Winkle \& Ozmun, 2003). The purpose of the study was to determine the impact of an 8 -week judo course on the muscular endurance, trunk flexibility, and explosive strength of male university students.

\section{Methods}

\section{Participants and assessment}

The participants were all college-level students who registered for the judo class offered by the University. None of them were PE majors. Pre and post measurements were obtained for standing long jump, sit-ups, and sit and reach to assess explosive strength, abdominal muscle endurance, and flexibility, respectively.

\section{Ethics}

The study was conducted in accordance with the Declaration of Helsinki. This study was approved in advance by the Ethical Committee of the Physical Education Department of KFUPM. Each participant voluntarily provided a written informed consent before participating. The privacy of the students was guaranteed.

\section{Judo course}

The course was done twice a week for eight weeks. Each session was 50 minutes and had different training drills. Fitness training was achieved by asking the students to do 50 push-ups and 100 sit-ups. Stretching exercises and rolling/falling technique was done for 10 minutes to train for flexibility. Judo technique steps were taught to train for agility. Three minutes 
free spar was used to train for strength and endurance, while cardiovascular training was done with five minutes running, jump rope, and jumping jack. Standing and ground judo techniques were taught to the students to train for agility, strength, endurance, and flexibility.

\section{Data Analysis}

The data were tested for normality using the Shapiro-Wilk Test. Normal pre and post data were compared using the paired t-test, while non-normal data were compared with the Wilcoxon Signed Rank Test. Alpha values were set at 0.05 , and Cohen $\mathrm{d}>0.2$ was considered of practical significance.

\section{Results}

Twenty students had complete data at the end of the course. All data were compared with the paired t-test. Table 1 shows the means of the pre and post data for the measured variables, and the results of the comparison between them. There were statistically significant improvements $(p<0.05)$ in all parameters.

Table 1. Data of selected health-related fitness variables $(\mathrm{N}=20)$

\begin{tabular}{|c|c|c|c|c|c|c|}
\hline Test Exercise & Pre & Post & $\mathrm{p}$ value & $95 \% \mathrm{CI}$ & $\begin{array}{c}\text { Percentage } \\
\text { Improvement }\end{array}$ & Cohen d \\
\hline Standing Long Jump (cm) & $168.1(26.3)$ & $183.15(30.5)$ & $0.002 *$ & {$[6.3,23.8]$} & 9 & 0.81 \\
\hline Sit Ups (repetitions) & $24(6)$ & $28(4)$ & $0.001 *$ & {$[2,7]$} & 19.4 & 0.90 \\
\hline Sit and Reach $(\mathrm{cm})$ & $23(8)$ & $28(7)$ & $0.004 *$ & {$[1,7]$} & 17.5 & 0.72 \\
\hline
\end{tabular}

Note. All data in mean (standard deviation). $\mathrm{CI}=$ Confidence interval. $* \mathrm{p}<0.05$

\section{Discussion}

The research aimed at determining the effect of a judo PE course after 8 weeks on the following health-related fitness parameters: explosive strength, muscular endurance, and flexibility. The improvements from pre to post in standing long jump, sit-ups, and sit and reach indicate that the explosive strength, muscular endurance, and trunk flexibility of the students improved, respectively. This showed evidence that the course positively influenced these health-related fitness parameters.

Demiral (2011) reported an improvement in explosive strength among 7-12-year-old children who participated in a 12 months judo program. Masleša, Videmšek and Karpljuk (2012) reported improvements in sit-ups, sit and reach, and standing long jump among intellectually disabled people after performing the program for eight weeks.

These improvements can be accounted for by the nature of the exercises done in the course. Performing standing and ground judo practices requires flexibility, strength, and endurance for execution. The continuous training of the students to enable them execute the judo techniques properly can explain the improvements in the measured parameters.

There are additional reasons for the observed improvements. A reason for muscular endurance improvements can be attributed to the 100 sit ups which were done during the sessions. The explosive strength improvements are also as a result

\section{R E F E R E N C E S}

Degoutte, F., Jouanel, P., \& Filaire, E. (2003). Energy demands during a judo match and recovery. British Journal of Sports Medicine, 37(3), 245-249. https://doi.org/10.1136/bjsm.37 .3 .245

Demiral, S. (2011). The Study of the Effects of Educational Judo Practices on Motor Abilities of 7-12 Years Aged Judo Performing Children. Asian Social Science, 7(9), 212. https://doi.org/10.5539/ass.v7n9p212

Franchini, E., Del Vecchio, F.B., Matsushigue, K.A., \& Artioli, G.G. (2011). Physiological Profiles of Elite Judo Athletes. Sports Medicine; Auckland, 41(2), 147-66. https://doi.org/ http://dx.doi.org/10.2165/11538580-000000000-00000

Franchini, E., Takito, M.Y., Kiss, M., \& Strerkowicz, S. (2005). Physical fitness and anthropometrical differences between of the 3 minutes sparring sessions. The 10 minutes stretching exercise per session, and teaching the rolling/falling technique contributed in improving the flexibility of the students. The students acquired more musculoskeletal fitness which will help them execute other activities (Warburton et al., 2006).

Because the course was for students, this study cannot be compared with elite players. More importantly, the aim of the PE judo course was to promote physical activity and improve the health of the university students; not to train them as athletes. Despite these improvements from pre to post, a limitation of the study is the absence of a control group.

The judo course improved the trunk flexibility, explosive strength, and muscle endurance of the students, which are needed for judo and for healthy living. Even though the participants are not judo athletes, the benefits they got from the course improved some aspects of their health-related fitness. These results provide evidence that judo is a good sport to be included in a PE program.

\section{Acknowledgements}

The authors thank the Deanship of Scientific Research of the King Fahd University of Petroleum \& Minerals, Dhahran, Saudi Arabia for supporting this research.

elite and non-elite judo players. Biology of Sport, 22(4), 315.

Haskell, W.L., Lee, I.-M., Pate, R.R., Powell, K.E., Blair, S.N., Franklin, B.A., ... Bauman, A. (2007). Physical Activity and Public Health: Updated Recommendation for Adults from the American College of Sports Medicine and the American Heart Association. Medicine \& Science in Sports \& Exercise, 39(8), 1423-1434. https://doi.org/10.1249/mss $.0 \mathrm{~b} 013 \mathrm{e} 3180616 \mathrm{~b} 27$

Masleša, S., Videmšek, M., \& Karpljuk, D. (2012). Motor abilities, movement skills and their relationship before and after eight weeks of martial arts training in people with intellectual disability. Acta Gymnica, 42(2), 15-26. https://doi .org/10.5507/ag.2012.008 
Warburton, D.E.R., Nicol, C.W., \& Bredin, S.S.D. (2006). Health benefits of physical activity: the evidence. Canadian Medical Association Journal, 174(6), 801-809. https://doi .org/10.1503/cmaj.051351

Winkle, J.M., \& Ozmun, J.C. (2003). Martial arts: An exciting addition to the physical education curriculum. Journal of
Physical Education, Recreation \& Dance; Reston, 74(4), 29-35.

World Health Organization. (2016, June). WHO | Obesity and overweight. Retrieved March 14, 2017, from http://www .who.int/mediacentre/factsheets/fs $311 / \mathrm{en} /$

M.H.H. Mohammed

King Fahd University of Petroleum \& Minerals, Physical Education Department, PO Box 1366, 31261 Dhahran, Saudi Arabia e-mail:hamdan@kfupm.edu.sa 
